\title{
Paclitaxel plus nedaplatin vs. paclitaxel plus carboplatin in women with epithelial ovarian cancer: A multi-center, randomized, open-label, phase III trial
}

\author{
LI LI $^{1 *}$, QINGQING ZHUANG ${ }^{2 *}$, ZEYI CAO ${ }^{3 *}$, RUTIE YIN $^{4}$, YAPING ZHU ${ }^{5}$, \\ LIRONG ZHU ${ }^{6}$, XING XIE ${ }^{7}$, YOUZHONG ZHANG ${ }^{8}$, LI LI $^{9}$, QIANG WU ${ }^{10}$, JIANHUA ZHENG $^{11}$, \\ QI ZHOU ${ }^{12}$, XIAOPING LI ${ }^{13}$, LINGYING WU ${ }^{14}$, YOUJI FENG ${ }^{5}$ and CHANGYU WANG ${ }^{15}$
}

${ }^{1}$ Department of Gynecology, Cancer Hospital of Guangxi Medical University, Nanning, Guangxi 530021;

${ }^{2}$ Department of Gynecology, The First People's Hospital of Jining, Jining, Shandong 272000; ${ }^{3}$ Department of Gynecology,

The Second Affiliated Hospital of Tsinghua University, Beijing 100049; ${ }^{4}$ Department of Gynecology,

West China Second University Hospital, Sichuan University, Chengdu, Sichuan 610041; ${ }^{5}$ Department of Gynecology, Shanghai General Hospital, Shanghai 200080; ${ }^{6}$ Department of Gynecology, Peking University First Hospital, Beijing 100034;

${ }^{7}$ Department of Gynecology, Women's Hospital School of Medicine Zhejiang University, Hangzhou, Zhejiang 310006;

${ }^{8}$ Department of Gynecology, Qilu Hospital of Shandong University, Jinan, Shandong 250012; ${ }^{9}$ Department of Gynecology,

Daping Hospital, Research Institute of Surgery Third Military Medical University, Chongqing 400042; ${ }^{10}$ Department of Gynecology, Jiangsu Cancer Hospital, Nanjing, Jiangsu 210009; ${ }^{11}$ Department of Gynecology, The First Affiliated Hospital of Harbin Medical University, Harbin, Heilongjiang 150001; ${ }^{12}$ Department of Gynecology, Peking University People's Hospital, Beijing 100044; ${ }^{13}$ Department of Gynecology, Chongqing Cancer Hospital, Chongqing 400030; ${ }^{14}$ Department of Gynecology,

Cancer Hospital, Chinese Academy of Medical Sciences, Beijing 100021; ${ }^{15}$ Department of Obstetrics and Gynecology, Tongji Hospital, Tongji Medical College, Huazhong University of Science and Technology, Wuhan, Hubei 430030, P.R. China

Received June 8, 2016; Accepted September 13, 2017

DOI: $10.3892 / \mathrm{ol} .2018 .7761$

\begin{abstract}
The multi-center, randomized, open-label, phase III trial discussed in the present study was performed to compare the clinical outcomes of nedaplatin (NDP) plus paclitaxel, and carboplatin (CBP) plus paclitaxel for the treatment of epithelial ovarian cancer (EOC). In the current study, 182 patients with International Federation of Gynecology and Obstetrics (FIGO) stage II-IV EOC were randomly assigned to receive NDP plus paclitaxel or CBP plus paclitaxel at 3-week intervals for a total of six courses. The primary endpoints were progression-free
\end{abstract}

Correspondence to: Dr Youji Feng, Department of Gynecology, Shanghai General Hospital, 100 Haining Road, Shanghai 200080, P.R. China

E-mail: fengyj4806@ sohu.com

Dr Changyu Wang, Department of Obstetrics and Gynecology, Tongji Hospital, Tongji Medical College, Huazhong University of Science and Technology, 1095 Jie Fang Avenue, Wuhan, Hubei 430030, P.R. China

E-mail: tjwangcy@sina.com

*Contributed equally

Key words: epithelial ovarian cancer, nedaplatin, carboplatin, paclitaxel, chemotherapy survival rate (PFS) and overall survival rate (OS). The secondary endpoints were toxicity profiles. The median follow-up was 44.63 months [95\% confidence interval (CI) 33.67-46.47 months] for the NDP group and 47.63 months $(95 \%$ CI 45.13-49.07 months) for the CBP group. Overall, there was no significant difference in PFS or OS between the two groups ( $\mathrm{P}=0.09$ for $\mathrm{PFS}$, and $\mathrm{P}=0.65$ for $\mathrm{OS}$ ). For the patients with FIGO stage III-IV EOC, the NDP plus paclitaxel regimen significantly prolonged PFS $(\mathrm{P}=0.02)$ but did not result in improved OS $(\mathrm{P}=0.53)$ when compared with the CBP group. The patients in the NDP plus paclitaxel group also exhibited a lower incidence rate of grade 3 or 4 leucopenia $(\mathrm{P}=0.03)$. Other hematological and non-hematological toxicity profiles were similar between the two groups. Compared with CBP plus paclitaxel regimens, NDP plus paclitaxel regimens achieved comparable survival outcomes and similar toxicity profiles. However, patients of FIGO stage III-IV EOC may experience more clinical benefits from NDP plus paclitaxel treatment, including a prolonged PFS and a lower incidence rate of leucopenia. Therefore, an NDP-based regimen may be an alternative choice when using platinum-based agents to treat EOC.

\section{Introduction}

Epithelial ovarian cancer (EOC) is one of the three most common malignant tumors of the female reproductive system (1). Owing to the lack of early diagnosis modalities 
and effective treatment measures, $>70 \%$ of the patients are diagnosed at an advanced disease stage, and this is associated with high rates of morbidity and mortality (2). At present, the standard therapy for advanced ovarian cancer usually includes primary surgical cytoreduction and chemotherapy $(3,4)$. The two-drug combination of paclitaxel and carboplatin (CBP) is considered the standard first-line chemotherapy for patients with EOC (5). Although this standard chemotherapy initially yields a high response rate $(>80 \%),>70 \%$ of women with advanced-stage EOC experience recurrence within 5 years and develop drug resistance $(2,6)$. This regimen has been associated with serious adverse effects including myelosuppression, alopecia, neurotoxicity and fatigue, which affect the tolerance of patients to the therapy, and their quality of life. Therefore, it is necessary to search for chemotherapy regimens with superior safety and efficacy for the treatment of EOC.

Nedaplatin, namely 254-S, NDP (cisplatin analogue), is a second-generation platinum derivative developed by Shionogi \& Co., Ltd. (Osaka, Japan). Experiments in vitro demonstrated that NDP inhibited tumor cell proliferation in human cervical and ovarian cancer $(7,8)$. In vivo, NDP exhibited an antitumor effect in tumor-bearing animals $(9,10)$. Results of phase II studies in Japan revealed that NDP exerted pronounced antitumor activity against various solid tumors, including lung, esophageal, head and neck, testicular, and cervical cancer, and ovarian carcinoma (11-16). Response rates of at least $25 \%$ have been achieved with $100 \mathrm{mg} / \mathrm{m}^{2} \mathrm{NDP}$ monotherapy in a range of different types of cancer (17). The response rate to NDP monotherapy was 38 and $34-46 \%$ in ovarian and cervical cancer, respectively $(11,13)$. Furthermore, NDP has been reported to exhibit higher antitumor activity in cervical cancer compared with CBP $(18,19)$.

On the basis of the above results, a multi-center, randomized, open-label phase III trial was designed to compare the clinical outcomes of NDP plus paclitaxel and CBP plus paclitaxel in the treatment of epithelial ovarian cancer. The trial was designed to test whether the efficacy and tolerability of NDP was maintained in combination with paclitaxel. The endpoints, including progression-free survival (PFS), overall survival (OS), and toxicity profiles, were compared between the two groups to provide further evidence for the clinical application of NDP.

\section{Patients and methods}

Patients. A total of 182 patients with epithelial ovarian cancer [International Federation of Gynecology and Obstetrics (FIGO) stage II-IV] (20) were enrolled between August 2010 and April 2012 at 14 centers (Cancer Hospital of Guangxi Medical University, Nanning; Tongji Hospital, Shanghai; West China Second University Hospital, Chengdu; Shanghai General Hospital, Shanghai; Peking University First Hospital, Beijing; Women's Hospital School of Medicine Zhejiang University, Hangzhou; Qilu Hospital of Shandong University, Jinan; Daping Hospital, Research Institute of Surgery Third Military Medical University, Chongqing; Jiangsu Cancer Hospital, Nanjing; The First Affiliated Hospital of Haerbin Medical University, Haerbin; Chongqing Cancer Hospital, Chongqing; Cancer Hospital Chinese Academy of Medical Science, Beijing; The Second Affiliated Hospital of Tsinghua
University, Beijing; Peking University People's Hospital, Beijing), in China. Clinicopathological characteristics are presented in Table I. A computer-based minimization procedure was used to randomly allocate participants at a 1:1 ratio to either the standard schedule of CBP plus paclitaxel or the experimental schedule of NDP plus paclitaxel. The procedure of centralized randomization was conducted by the Department of Biostatistics, Nanjing Medical University (Nanjing, China). The ethics committee of each participating center approved the study protocol. Written informed consent was obtained from every participant prior to enrolment and randomization. The main inclusion criteria were as follows: i) Patients had pathologically or cytologically confirmed epithelial ovarian cancer [The International Federation of Gynecology and Obstetrics (FIGO) stage II-IV] followed by optimal cytoreductive surgery; ii) patients were aged between 18 and 70 years old; and iii) patients exhibited adequate hematological, renal, and hepatic function. In addition, all included patients had no other serious medical problems, and no intracranial or bone metastases. Good adherence, regular follow-up and voluntary compliance with the provisions of this research were required. Patients were excluded it they failed to complete the planned cycles because of progressive disease or any other reason. Patients who were pregnant or lactating were also excluded from the present study. The trial was registered with the Chinese Clinical Trial Registry (no. ChiCTR-TRC-11001333).

Therapeutic regimens. All drugs were obtained from Jiangsu Aosaikang Pharmaceutical Co., Ltd. (Nanjing, China). Patients assigned to the experimental group (NDP group) received paclitaxel $\left(175 \mathrm{mg} / \mathrm{m}^{2}\right)$ plus NDP $\left(80 \mathrm{mg} / \mathrm{m}^{2}\right)$ whereas patients in the control group (CBP group) received paclitaxel $\left(175 \mathrm{mg} / \mathrm{m}^{2}\right)$ plus CBP [area under the curve (AUC) $5 \mathrm{mg} / \mathrm{ml}$ per min according to the Calvert formula] (21). Creatinine clearance was estimated according to the Cockcroft-Gault formula (22). The treatment was administered once every 3 weeks for a total of six cycles. NDP was dissolved in $500 \mathrm{ml}$ of normal saline prior to use and infused over $2 \mathrm{~h}$. To avoid kidney damage, particularly in patients producing $<1,500 \mathrm{ml}$ urine per $24-\mathrm{h}$, $>1,000 \mathrm{ml}$ intravenous infusion of paclitaxel $\left(80 \mathrm{mg} / \mathrm{m}^{2}\right)$ plus NDP $\left(80 \mathrm{mg} / \mathrm{m}^{2}\right)$ was administered following administration of NDP. Paclitaxel was diluted in $500 \mathrm{ml} \mathrm{5 \%} \mathrm{glucose} \mathrm{diluted}$ in hydrochloric acid water prior to intravenous drip administration for at least $3 \mathrm{~h}$. To prevent paclitaxel-associated allergic reactions, the patients were orally pre-medicated with $10 \mathrm{mg}$ dexamethasone $12 \mathrm{~h}$ prior to paclitaxel infusion and $30 \mathrm{~min}$ prior to paclitaxel infusion with $10 \mathrm{mg}$ dexamethasone by intravenous injection, $400 \mathrm{mg}$ diphenhydramine by intravenous infusion and $20 \mathrm{mg}$ cimetidine by intramuscular injection. CBP was infused intravenously in $500 \mathrm{ml} \mathrm{5 \%}$ glucose diluted in hydrochloric acid water over $2 \mathrm{~h}$. To assess the risk of acute toxic effects, hematological measurements were performed at every administration of chemotherapy. An absolute neutrophil count of $>1.5 \times 10^{9}$ cells $/ 1$, a white blood cell count of $>3.0 \times 10^{9}$ cells $/ 1$ and a platelet count of $>100 \times 10^{9}$ cells $/ 1$ at the beginning of treatment were required for patients; otherwise, treatment was delayed until the required hematological counts were achieved. Treatment delay was permitted because pronounced toxic effects in patients require a treatment discontinuation of 2 weeks or longer. In the two study groups, 
Table I. Patient characteristics.

\begin{tabular}{|c|c|c|c|}
\hline Characteristic & NDP group & CBP group & $\mathrm{P}$-value \\
\hline Age, years & $50.82 \pm 9.83^{\mathrm{a}}$ & $50.84 \pm 10.30^{\mathrm{a}}$ & 0.98 \\
\hline \multicolumn{4}{|l|}{ FIGO stage, n (\%) } \\
\hline II & $28(30.77)$ & $19(21.11)$ & \multirow[t]{3}{*}{0.66} \\
\hline III & $52(57.14)$ & $67(74.44)$ & \\
\hline IV & $12(12.09)$ & $4(4.44)$ & \\
\hline \multicolumn{4}{|l|}{ Treatment status, n (\%) } \\
\hline Initial treatment & $86(93.48)$ & $86(95.56)$ & \multirow[t]{2}{*}{0.75} \\
\hline Retreatment & $6(6.52)$ & $4(4.44)$ & \\
\hline \multicolumn{4}{|l|}{ Marital status, n (\%) } \\
\hline Married & $91(98.91)$ & $86(95.56)$ & \multirow[t]{2}{*}{0.21} \\
\hline Unmarried & $1(1.09)$ & $4(4.44)$ & \\
\hline \multicolumn{4}{|l|}{ Background disease, n (\%) } \\
\hline No & $76(82.61)$ & $76(84.44)$ & \multirow[t]{2}{*}{0.84} \\
\hline Yes & $16(17.39)$ & $14(15.56)$ & \\
\hline \multicolumn{4}{|l|}{ Operation, n (\%) } \\
\hline No & $42(45.65)$ & $42(46.67)$ & \multirow[t]{2}{*}{1.00} \\
\hline Yes & $50(54.35)$ & $48(53.33)$ & \\
\hline \multicolumn{4}{|l|}{ Radiotherapy, n (\%) } \\
\hline No & $92(100.00)$ & $90(100.00)$ & \multirow[t]{2}{*}{-} \\
\hline Yes & $0(0.00)$ & $0(0.00)$ & \\
\hline \multicolumn{4}{|l|}{ Chemotherapy, n (\%) } \\
\hline No & $73(79.35)$ & $71(78.89)$ & \multirow[t]{2}{*}{1.00} \\
\hline Yes & $19(20.65)$ & $19(21.11)$ & \\
\hline \multicolumn{4}{|l|}{ Biotherapy, n (\%) } \\
\hline No & $92(100.00)$ & $90(100.00)$ & \multirow[t]{2}{*}{-} \\
\hline Yes & $0(0.00)$ & $0(0.00)$ & \\
\hline \multicolumn{4}{|l|}{ History of drug allergy, n (\%) } \\
\hline No & $85(92.39)$ & $86(95.56)$ & \multirow[t]{2}{*}{0.54} \\
\hline Yes & $7(7.61)$ & $4(4.44)$ & \\
\hline \multicolumn{4}{|c|}{ Pathological/cytological patterns, n (\%) } \\
\hline Serous adenocarcinoma & $57(62.64)$ & $58(65.17)$ & \multirow[t]{5}{*}{0.53} \\
\hline Mucinous adenocarcinoma & $7(7.69)$ & $4(4.49)$ & \\
\hline Clear-cell carcinoma & $7(7.69)$ & $3(3.37)$ & \\
\hline Endometrioid adenocarcinoma & $7(7.69)$ & $11(12.36)$ & \\
\hline Other & $14(14.29)$ & $14(14.61)$ & \\
\hline \multicolumn{4}{|l|}{ ECOG score, n (\%) } \\
\hline 0 & $69(75.00)$ & $60(66.67)$ & \multirow[t]{3}{*}{0.19} \\
\hline 1 & $23(25.00)$ & $28(31.11)$ & \\
\hline 2 & $0(0.00)$ & $2(2.22)$ & \\
\hline \multicolumn{4}{|l|}{ Treatment cycles, n (\%) } \\
\hline 1 & $8(8.70)$ & $3(3.33)$ & \multirow[t]{6}{*}{0.07} \\
\hline 2 & $5(5.43)$ & $4(4.44)$ & \\
\hline 3 & $0(0.00)$ & $1(1.11)$ & \\
\hline 4 & $10(10.87)$ & 8 (8.89) & \\
\hline 5 & $10(10.87)$ & $5(5.56)$ & \\
\hline 6 & $59(64.13)$ & 69 (76.67) & \\
\hline
\end{tabular}

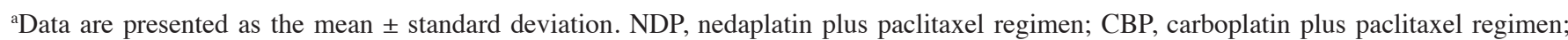
FIGO, International Federation of Gynecology and Obstetrics. ECOG, Eastern Cooperative Oncology Group. 

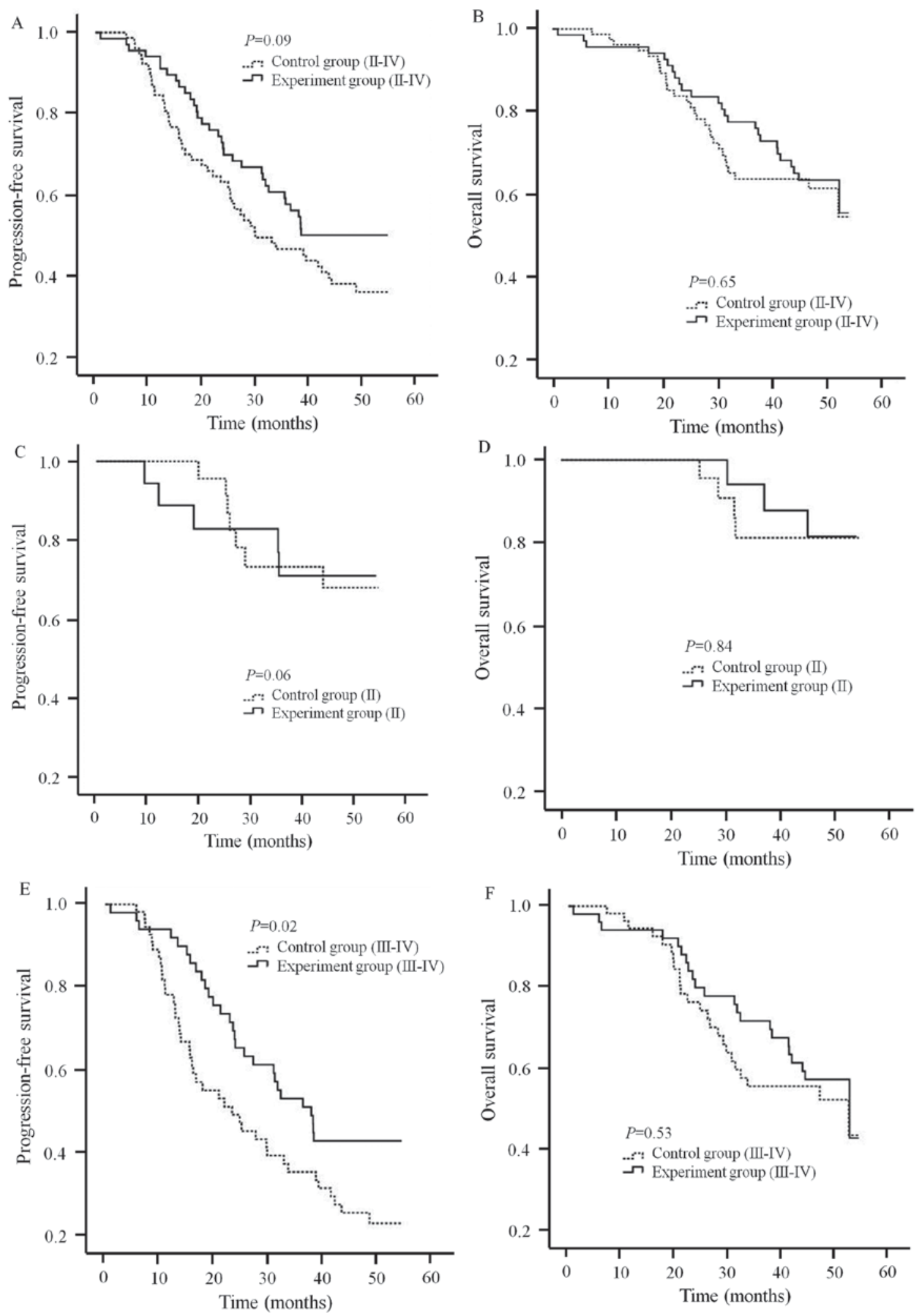

Figure 1. Kaplan-Meier analysis of PFS and OS rate in patients with advanced epithelial ovarian cancer, categorized by treatment schedule. Comparisons were performed using the log-rank test. (A) PFS and (B) OS of all patients in the control (carboplatin plus paclitaxel) and experimental (nedaplatin plus paclitaxel) groups. (C) PFS and (D) OS of the patients with FIGO stage II ovarian cancer. (E) PFS and (F) OS of the patients with FIGO stage III-IV ovarian cancer. PFS, progression-free survival; OS, overall survival; FIGO, International Federation of Gynecology and Obstetrics.

the doses of all drugs were reduced by $20 \%$ if the neutrophil count fell to $<0.5 \times 10^{9}$ cells $/ 1$ or platelet count to $<50 \times 10^{9}$ cells $/ 1$ for 7 days or longer. The drug doses were reduced by $25 \%$ if grade 2 neuropathy arose. Chemotherapy was continued until unacceptable toxicity was observed, or the patient refused further treatment. 
Table II. Comparison of adverse reactions between the two groups.

Classification

of adverse reaction

\begin{tabular}{|c|c|c|c|c|c|c|c|c|c|c|c|}
\hline Symptom & Group & 0 & $\mathrm{I}$ & II & III & IV & Total & Incidence $(\%)$ & P-value & Grade III-IV incidence (\%) & P-value \\
\hline \multirow[t]{2}{*}{ Leukocyte } & NDP & 16 & 30 & 36 & 9 & 1 & 92 & 82.61 & \multirow[t]{2}{*}{0.69} & 10.87 & \multirow[t]{2}{*}{0.03} \\
\hline & $\mathrm{CBP}$ & 13 & 24 & 32 & 20 & 1 & 90 & 85.56 & & 23.33 & \\
\hline \multirow[t]{2}{*}{ Thrombocyte } & NDP & 58 & 21 & 8 & 5 & 0 & 92 & 36.96 & \multirow[t]{2}{*}{0.37} & 5.43 & \multirow[t]{2}{*}{0.28} \\
\hline & $\mathrm{CBP}$ & 50 & 21 & 10 & 9 & 0 & 90 & 44.44 & & 10.00 & \\
\hline \multirow[t]{2}{*}{ Granulocyte } & NDP & 22 & 25 & 22 & 16 & 7 & 92 & 76.09 & \multirow[t]{2}{*}{0.47} & 25.00 & \multirow[t]{2}{*}{0.08} \\
\hline & $\mathrm{CBP}$ & 17 & 11 & 28 & 19 & 15 & 90 & 81.11 & & 37.78 & \\
\hline \multirow[t]{2}{*}{ Hemoglobin } & NDP & 14 & 27 & 43 & 8 & 0 & 92 & 84.78 & \multirow[t]{2}{*}{1.00} & 8.70 & \multirow[t]{2}{*}{0.63} \\
\hline & $\mathrm{CBP}$ & 14 & 29 & 37 & 8 & 2 & 90 & 84.44 & & 11.11 & \\
\hline \multirow[t]{2}{*}{ TBIL } & NDP & 87 & 0 & 5 & 0 & 0 & 92 & 5.43 & \multirow[t]{2}{*}{0.77} & 0 & \multirow[t]{2}{*}{0.50} \\
\hline & $\mathrm{CBP}$ & 84 & 0 & 5 & 1 & 0 & 90 & 6.67 & & 1.11 & \\
\hline \multirow[t]{2}{*}{ Creatinine } & NDP & 89 & 3 & 0 & 0 & 0 & 92 & 3.26 & \multirow[t]{2}{*}{0.25} & 0 & \multirow[t]{2}{*}{-} \\
\hline & $\mathrm{CBP}$ & 90 & 0 & 0 & 0 & 0 & 90 & 0 & & 0 & \\
\hline \multirow[t]{2}{*}{ ALT } & NDP & 60 & 31 & 1 & 0 & 0 & 92 & 34.78 & \multirow[t]{2}{*}{1.00} & 0 & \multirow[t]{2}{*}{-} \\
\hline & $\mathrm{CBP}$ & 59 & 30 & 1 & 0 & 0 & 90 & 34.44 & & 0 & \\
\hline \multirow[t]{2}{*}{$\mathrm{AST}$} & NDP & 67 & 25 & 0 & 0 & 0 & 92 & 27.17 & \multirow[t]{2}{*}{0.39} & 0 & \multirow[t]{2}{*}{-} \\
\hline & $\mathrm{CBP}$ & 71 & 19 & 0 & 0 & 0 & 90 & 21.11 & & 0 & \\
\hline \multirow[t]{2}{*}{ Nausea/vomiting } & NDP & 24 & 48 & 17 & 3 & 0 & 92 & 73.91 & \multirow[t]{2}{*}{0.51} & 3.26 & \multirow[t]{2}{*}{0.50} \\
\hline & CBP & 28 & 38 & 19 & 4 & 1 & 90 & 68.89 & & 5.56 & \\
\hline \multirow[t]{2}{*}{ Peripheral nervous system } & NDP & 71 & 17 & 4 & 0 & 0 & 92 & 22.83 & \multirow[t]{2}{*}{1.00} & 0 & \multirow[t]{2}{*}{-} \\
\hline & $\mathrm{CBP}$ & 69 & 19 & 2 & 0 & 0 & 90 & 23.33 & & 0 & \\
\hline
\end{tabular}

NDP, nedaplatin plus paclitaxel regimen; CBP, carboplatin plus paclitaxel regimen; TBIL, total bilirubin; ALT, alanine transaminase; AST, aspartate transaminase.

Evaluation indicators and statistical analysis. The primary objective of the present study was to compare PFS and OS between the two treatment groups. Secondary endpoints were toxicity profiles. PFS was defined as the interval between the first day of randomization and date of first relapse, progression or death (whichever occurred first) or the date of the last follow-up for patients alive at the end of the study without progression. Surviving patients or patients lost to follow-up were censored at the date last known to be alive. Descriptive data were presented as frequencies and percentages. Patient characteristics in the two groups were compared using Pearson's $\chi^{2}$ test. Differences in OS and PFS were calculated using Kaplan-Meier curves and compared using the log-rank test. All P-values were two-tailed and $\mathrm{P}<0.05$ was considered to indicate a statistically significant difference. All analyses were conducted by independent third-party statisticians from the Department of Biostatistics, Nanjing Medical University, using SPSS 19.0 software (IBM Corp, Armonk, NY, USA).

\section{Results}

Characteristics of patients. The randomized, multi-center, open-label, phase III trial analyzed 182 patients with EOC between August 2010 and April 2012. Of these patients, 92 received NDP plus paclitaxel regimens and 90 received
CBP plus paclitaxel regimens. The patient characteristics are presented in Table I. No statistical difference was observed between the two groups with regard to age, FIGO stage, initial treatment or retreatment, marital status, background disease or complications, history of drug allergies, pathological patterns or Eastern Cooperative Oncology Group score (23). All enrolled patients received between 1 and 6 cycles of chemotherapy. The chemotherapy duration was $5.02 \pm 1.63$ [mean \pm standard deviation (SD)] cycles in the NDP group and 5.39 \pm 1.30 (mean $\pm \mathrm{SD}$ ) cycles in the CBP group $(\mathrm{P}=0.07$; Table I). A number of patients received surgery, radiotherapy, chemotherapy, biotherapy or other treatments prior to the trial, but there was no statistical difference between the two groups (Table I).

Response to treatment and survival. In the present study, the date of last the follow-up was May 20,2015. A small proportion of the patients $(35 / 182)$ were lost to the follow-up due to loss of contact, and their data were thus excluded from the survival analysis. There was no statistically significant difference in censoring or lost-to-follow up status between the two groups (data not shown). The median follow-up times for the NDP group and CBP group were 44.63 months [95\% confidence interval (CI): 33.67-46.47 months] and 47.63 months (95\% CI: 45.13-49.07 months), respectively. 
With respect to the primary endpoints, the difference in the 5-year OS or PFS rate was not significant between the NDP and the CBP groups. The PFS rate in the NDP group $(50.20 \%)$ was not statistically different from that of the CBP group (36.20\%; Fig. 1A; $\mathrm{P}=0.09$ ), as revealed by Kaplan-Meier analysis. Similarly, the 5 -year OS rate was $63.5 \%$ in the NDP group and $61.5 \%$ in the CBP group. Although the NDP group exhibited a higher OS rate than the CBP group, no statistical difference was observed between the two groups (Table II and Fig. 1B; $\mathrm{P}=0.65$ ). Thus, the two treatment groups had the same effect in terms of prolonging the lifespan of patients, and delaying the progression of EOC.

Stratification analysis was further performed according to FIGO stage. For patients with FIGO II stage EOC, the PFS and OS were not statistically different between the NDP group and the CBP group ( $\mathrm{P}=0.06$ for $\mathrm{PFS}, \mathrm{P}=0.84$ for $\mathrm{OS}$; Fig. 1C and D). For the patients with FIGO stage III-IV EOC, the OS rate in the two groups did not significantly differ (Fig. 1F; $\mathrm{P}=0.53$ ). However, the PFS rate in the NDP group was significantly higher than the $\mathrm{CBP}$ group (Fig. 1E; $\mathrm{P}=0.02$ ).

Toxicity profiles. With respect to the secondary endpoints, the hematological and non-hematological toxicity profiles were summarized in Table II. A significant difference was observed in the white blood cell count and occurrence of grade 3 or 4 leucopenia between the two groups. The incidence of leucopenia was higher in the CBP group than the NDP group (23.33 vs. $10.87 \%$; $\mathrm{P}<0.05)$. The rate of granulopenia, thrombocytopenia, hemoglobinemia and nausea/vomiting tended to be lower in the NDP group when compared with the CBP group; however, no statistical difference was observed between the two groups. Furthermore, no grade 3 or 4 renal toxicity or neurotoxicity was observed in the two groups.

\section{Discussion}

EOC is the most lethal gynecological malignancy and is sensitive to chemotherapy. Survival is markedly improved when a combination of paclitaxel and platinum-based chemotherapy is administered as a first-line therapy. Even so, the rates of recurrence and mortality remain high $(24,25)$. Thus, improved treatments for this disease are required. One option is to substitute NDP for CBP, as has been done in the present study. The present phase III trial intended to compare the clinical efficacy of the experimental regimen of NDP plus paclitaxel and the control regimen of CBP plus paclitaxel as first-line treatments for patients with EOC.

According to previous studies, the median PFS time was 16-21 months and the median OS time was 32-57 months in patients with advanced EOC (26-30). In the present study, the observed PFS time was longer (38.23 months for the NDP group and 29.80 months for the CBP group), while the observed OS time was similar to the value previously reported (55.63 months for the NDP group and 55.10 months for the CBP group). The results of the present study indicated that prolonged PFS did not result in longer OS, a result also indicated in previous studies $(30,31)$.

Overall, there was no statistical difference in PFS and OS between the two groups. However, stratified analysis revealed that that the NDP treatment significantly extended PFS time of patients with FIGO stage III-IV EOC (37.90 compared with 23.33 months; $\mathrm{P}=0.02$ ). The observed survival benefits of NDP may be explained by increased compliance and the greater number of chemotherapy cycles that the patients received. Markman et al (32) reported that the incidence of hypersensitivity reactions (HSRs) against CBP increased with repeated treatment. In the present study, the patients who received NDP suffered less from leucopenia (Table II). It was also reported that NDP was less renally toxic and had relatively lower rate of neurotoxicity (33). Michikami et al (34) revealed that the substitution of NDP for CBP allowed for continued administration of platinum agents, hence the patients who were treated with NDP may complete more chemotherapy cycles than those treated with CBP.

In conclusion, the present multi-center, randomized, open-label phase III trial indicated that NDP-based regimens may be alternative platinum-based treatments for EOC. Compared with CBP plus paclitaxel regimens, NDP plus paclitaxel regimens achieved comparable survival outcomes and similar toxicity profiles. However, patients with FIGO stage III-IV disease may experience more clinical benefits, including prolonged PFS and a lower incidence rate of leucopenia, from NDP plus paclitaxel treatment.

\section{Acknowledgements}

The present study was supported by National Natural Science Foundation of China (grant. no. 81672580). The authors would like to thank the Department of Biostatistics, Nanjing Medical University (Nanjing, China) for performing the centralized randomization procedure.

\section{References}

1. Weiderpass $\mathrm{E}$ and Labrèche F: Malignant tumors of the female reproductive system. Saf Health Work 3: 166-180, 2012.

2. Heintz AP, Odicino F, Maisonneuve P, Quinn MA, Benedet JL, Creasman WT, Ngan HY, Pecorellu S and Beller U: Carcinoma of the ovary. FIGO 26th Annual Report on the Results of Treatment in Gynecological Cancer. Int J Gynecol Obstet 95 (Suppl 1): S161-S192, 2006.

3. Bookman MA, Brady MF, McGuire WP, Harper PG, Alberts DS, Friedlander M, Colombo N, Fowler JM, Argenta PA, De Geest K, et al: Evaluation of new platinum-based treatment regimens in advanced-stage ovarian cancer: A phase III trial of the Gynecologic Cancer Intergroup. J Clin Oncol 27: 1419-1425, 2009.

4. Bristow RE, Tomacruz RS, Armstrong DK, Trimble EL and Montz FJ: Survival effect of maximal cytoreductive surgery for advanced ovarian carcinoma during the platinum era: A meta-analysis. J Clin Oncol 20: 1248-1259, 2002.

5. Thigpen T, duBois A,McAlpine J,DiSaiaP,Fujiwara K,Hoskins W, Kristensen G, Mannel R, Markman M, Pfisterer J, et al: First-line therapy in ovarian cancer trials. Int J Gynecol Cancer 21: 756-762, 2011.

6. Monk BJ and Coleman RL: Changing the paradigm in the treatment of platinum-sensitive recurrent ovarian cancer: From platinum doublets to nonplatinum doublets and adding antiangiogenesis compounds. Int J Gynecol Cancer 19 (Suppl 2): S63-S67, 2009.

7. Monk BJ, Alberts DS, Burger RA, Fanta PT, Hallum AV III, Hatch KD and Salmon SE: In vitro phase II comparison of the cytotoxicity of a novel platinum analog, nedaplatin (254-S), with that of cisplatin and carboplatin against fresh, human cervical cancers. Gynecol Oncol 71: 308-312, 1998 . 
8. Alberts DS, Fanta PT, Running KL, Adair JL Jr, Garcia DJ, Liu-Stevens R and Salmon SE: In vitro phase II comparison of the cytotoxicity of a novel platinum analog, nedaplatin (254-S), with that of cisplatin and carboplatin against fresh, human ovarian cancers. Cancer Chemother Pharmacol 39: 493-497, 1997.

9. Uchida N, Yoshida H, Yamada H, Wada T, Daikatsu K, Ikeuchi I, Maekawa R, Sugita K and Yoshioka T: Combination chemotherapy with nedaplatin and cyclophosphamide in human ovarian cancer model. Jpn J Cancer Res 90: 887-894, 1999.

10. Uchida N, Yamada H, Maekawa R and Yoshioka T: Combination chemotherapy of paclitaxel followed by nedaplatin for human ovarian cancer. Gan To Kagaku Ryoho 29: 1943-1949, 2002 (In Japanese).

11. Noda K, Ikeda M, Yakushiji M, Nishimura H, Terashima Y, Sasaki H, Hata T, Kuramoto H, Tanaka K, Takahashi T, et al: A phase II clinical study of cis-diammine glycolato platinum, 254-S, for cervical cancer of the uterus. Gan To Kagaku Ryoho 19: 885-892, 1992. (In Japanese).

12. Inuyama $Y$, Miyake $H$, Horiuchi $M$, Hayasaki K, Komiyama S and Ota K: A late phase II clinical study of cis-diammine glycolato platinum, 254-S, for head and neck cancers. Gan To Kagaku Ryoho 19: 871-877, 1992 (In Japanese).

13. Kato T, Nishimura H, Yakushiji M, Noda K, Terashima Y, Takeuchi S, Takamizawa H, Suzuki M, Arai M, Ota M, et al: Phase II study of 254-S (cis-diammine glycolato platinum) for gynecological cancer. Gan To Kagaku Ryoho 19: 695-701, 1992 (In Japanese).

14. Taguchi T, Wakui A, Nabeya K, Kurihara M, Isono K, Kakegawa T and Ota K: A phase II clinical study of cis-diammine glycolato platinum, 254-S, for gastrointestinal cancers. 254-S Gastrointestinal Cancer Study Group. Gan To Kagaku Ryoho 19: 483-488, 1992 (In Japanese).

15. Akaza H, Togashi M, Nishio Y, Miki T, Kotake T, Matsumura Y, Yoshida $\mathrm{O}$ and Aso Y: Phase II study ofcis-diammine(glycolato) platinum, 254-S, in patients with advanced germ-cell testicular cancer, prostatic cancer, and transitional-cell carcinoma of the urinary tract. 254-S Urological Cancer Study Group. Cancer Chemother Pharmacol 31: 187-192, 1992.

16. Fukuda M, Shinkai T, Eguchi K, Sasaki Y, Tamura T, Ohe Y, Kojima A, Oshita F, Hara K and Saijo N: Phase II study of (glycolate-O,O,)diammineplatinum(II), a novel platinum complex, in the treatment of non-small-cell lung cancer. Cancer Chemother Pharmacol 26: 393-396, 1990.

17. Lebwohl D and Canetta R: Clinical development of platinum complexes in cancer therapy: An historical perspective and an update. Eur J Cancer 34: 1522-1534, 1998.

18. Hong WS, Min YI, Kim HT, Cho YB, Kim KH and Kim DK: Antitumor activity of five new platinum complexes having a glycolate leaving ligand. J Korean Med Sci 10: 269-274, 1995.

19. Weiss RB and Christian MC: New cisplatin analogues in development. A review. Drugs 46: 360-377, 1993.

20. Paik ES, Lee YY, Lee EJ, Choi CH, Kim TJ, Lee JW, Bae DS and Kim BG: Survival analysis of revised 2013 FIGO staging classification of epithelial ovarian cancer and comparison with previous FIGO staging classification. Obstet Gynecol Sci 58: 124-134, 2015.

21. Calvert AH, Newell DR, Gumbrell LA, O'Reilly S, Burnell M, Boxall FE, Siddik ZH, Judson IR, Gore ME and Wiltshaw E: Carboplatin dosage: Prospective evaluation of a simple formula based on renal function. J Clin Oncol 7: 1748-1756, 1989.

22. Cockcroft DW and Gault MH: Prediction of creatinine clearance from serum creatinine. Nephron 16: 31-41, 1976.

23. Giantonio BJ, Catalano PJ, Meropol NJ, O'Dwyer PJ , Mitchel EP, Alberts SR, Schwartz MA and Benson AB: Bevacizumab in combination with oxaliplatin, fluorouracil, and leucovorin (FOLFOX4) for previously treated metastatic colorectal cancer: Result from the Eastern Cooperative Oncology Group Study E3200. J Clin Oncol 25: 1539-1544, 2007.
24. Aghajanian C, Blank SV, Goff BA, Judson PL, Teneriello MG, Husain A, Sovak MA, Yi J and Nycum LR: OCEANS: A randomized, double-blinded, placebo-controlled phase III trial of chemotherapy with or without bevacizumab in patients with platinum-sensitive recurrent epithelial ovarian, primary peritoneal, or fallopian tube cancer. J Clin Oncol 30: 2039-2045, 2012.

25. Jemal A, Murray T, Ward E, Samuels A, Tiwari RC, Ghafoor A, Feuer EJ and Thun MJ: Cancer statistics, 2005. CA Cancer J Clin 55: 10-30, 2005.

26. Piccart MJ, Bertelsen K, Stuart G, Cassidy J, Mangioni C, Simonsen E, James K, Kaye S, Vergote I, Blom R, et al: Long-term follow-up confirms a survival advantage of the paclitaxel-cisplatin regimen over the cyclophosphamide-cisplatin combination in advanced ovarian cancer. Int J Gynecol Cancer 13 (Suppl 2): S144-S148, 2003.

27. Ozols RF, Bundy BN, Greer BE, Fowler JM, Clarke-Pearson D, Burger RA, Mannel RS, DeGeest K, Hartenbach EM and Baergen R; Gynecologic Oncology Group: Phase III trial of carboplatin and paclitaxel compared with cisplatin and paclitaxel in patients with optimally resected stage III ovarian cancer: A Gynecologic Oncology Group study. J Clin Oncol 21: 3194-3200, 2003.

28. du Bois A, Lück HJ, Meier W, Adams HR, Möbus V, Costa S, Bauknecht T, Richter B, Warm M, Schröder W, et al: A randomized clinical trial of cisplatin/paclitaxel versus carboplatin/paclitaxel as first-line treatment of ovarian cancer. J Natl Cancer Inst 95: 1320-1329, 2003

29. Neijt JP, Engelholm SA, Tuxen MK, Sorensen PG, Hansen M, Sessa C, de SwartCA, Hirsch FR, Lund B and van Houwelingen HC: Exploratory phase III study of paclitaxel and cisplatin versus paclitaxel and carboplatin in advanced ovarian cancer. J Clin Oncol 18: 3084-3092, 2000.

30. McGuire WP, Hoskins WJ, Brady MF, Kucera PR, Partridge EE, Look KY, Clarke-Pearson DL and Davidson M: Cyclophosphamide and cisplatin compared with paclitaxel and cisplatin in patients with stage III and stage IV ovarian cancer. New Engl J Med 334: 1-6, 1996.

31. Li Y and Zhang Q: A Weibull multi-state model for the dependence of progression-free survival and overall survival. Stat Med 34: 2497-2513, 2015

32. Markman M, Kennedy A, Webster K, Elson P, Peterson G, Kulp B and Belinson J: Clinical features of hypersensitivity reactions to carboplatin. J Clin Oncol 17: 1141, 1999.

33. Sasaki Y, Shinkai T, Eguchi K, Tamura T, Ohe Y, Ohmori T and Saijo N: Prediction of the antitumor activity of new platinum analogs based on their ex vivo pharmacodynamics as determined by bioassay. Cancer Chemother Pharmacol 27: 263-270, 1991

34. Michikami H, Minaguchi T, Ochi H, Onuku M, Okada S, Matsumoto K, Satoh T, Oki A and Yoshikawa H: Safety and efficacy of substituting nedaplatin after carboplatin hypersensitivity reactions in gynecologic malignancies. J Obstet Gynaecol Res 39: 330-335, 2013.

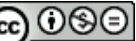

This work is licensed under a Creative Commons Attribution-NonCommercial-NoDerivatives 4.0 International (CC BY-NC-ND 4.0) License. 